\title{
Training in cardiology: the future
}

\section{The need for change}

The chief strength of training in British medicine in years past has been its emphasis on the practical experience which has been available in abundance to young doctors making their way within their chosen specialty. Several major changes in the National Health Service have made it essential that the whole process of training should be overhauled and tailored to the needs of junior doctors working in the new environment. The long overdue reduction in hours worked has substantially curtailed the clinical exposure available to junior doctors and we can no longer rely on a method of training that has in the past been almost entirely experiential. Some would say that this review was long overdue. Educationalists would be horrified to discover that young doctors embarking on a career in specialist medicine have never been offered any formal training in their specialty and baffled to find that the trainees were expected to proceed to consultant appointment without ever encountering a curriculum against which to monitor their acquisition of knowledge. Their misgivings would have been shared by most of the general public had they known that the progress of each junior doctor was governed more by their ability to convince interview panels of their proficiency rather than by any form of formal assessment of professional skills.

The publication of guidelines for training in cardiology, published in a supplement to the British Heart Fournal, is therefore to be welcomed. ${ }^{1}$ For the first time in the history of British cardiology, trainees beginning their training have a curriculum laid out for them with an indication of the subject matter that they should learn and understand as well as a guide to the numbers of practical procedures they should aim to undertake to become proficient.

Another driving force for change has come from Europe. It is now a requirement in all member countries of the European Union that medical trainees should receive a Certificate of Completion of Specialist Training (CCST) before being able to engage in independent specialty practice. The introduction of the CCST, as outlined in the Calman Report, has caused the Royal Colleges and the specialist societies to undertake a major review of the training programmes available to trainees in the United Kingdom. ${ }^{2}$ In Europe the training programmes in cardiology are substantially shorter than that envisaged for the United Kingdom but, in most countries, the certificate is awarded before much experience has been gained in invasive techniques such as coronary angiography, percutaneous transluminal coronary angioplasty, and cardiac pacing. Most European trainees will be eligible for certification after four years of training. In the United Kingdom a six year training scheme is planned and will include experience in invasive procedures as well as training in general internal medicine (GIM) so that, if required, trainees will be able to obtain dual certification in both the specialty of cardiology and in GIM. ${ }^{1}$ This is to ensure that United Kingdom trainees intending to practise in district general hospitals are able to combine the practice of their specialty with the respon- sibility for unselected takes of patients admitted to their hospitals with acute disease.

Even with a six year training programme, the total time spent before becoming eligible for a consultant appointment is likely to be shorter than has been the case before now, although there is some uncertainty about how long junior doctors will spend at the senior house officer grade. The period may also be extended if the trainee opts to take time out from the training programme to undertake more extensive research than the official progrămme demands.

\section{Assessment}

For a young doctor coming to a training scheme fresh from the rigours of A levels, qualifying examinations at medical school, and a postgraduate diploma in medicine (MRCP) systematic assessment may be an unwelcome prospect. If, however, the award of the CCST by the General Medical Council is to be an indication of the achievement of excellence that engenders confidence in patients and employers, then some form of assessment is essential. It is generally accepted that the alternative approach of an exit examination will prove too expensive and laborious for the already stretched resources of the Royal Colleges, particularly as cardiology is only one of many specialties devising new training schemes.

There are other cogent reasons why a system of assessment should be beneficial. In the past it has been possible for junior doctors to reach an advanced stage of their training period only to find out too late that they have chosen the wrong career. It is hoped that early assessment and counselling of trainees will avoid this calamity. Certainly assessments should provide a regular review of the trainee's personal and professional development: this will be better than waiting for problems to show themselves at a stage when it may be too late to rectify matters.

There will also be definite advantages to the trainee. Assessment panels will for the first time be able to discuss with trainees whether the departments in which they are working are providing the necessary training experience to allow them to complete their training. The conflict that already exists between service needs and training requirement will undoubtedly become more acute if, as predicted, the number of trainees employed in specialty training programmes falls. Any resulting deficiency in training is much more likely to come to light if there is an annual review of timetables and an assessment of whether these allow trainees to attain national standards and targets during training. The postgraduate deans and the Specialty Advisory Committees of the Royal College will continue to have a role in ensuring that training posts are designed appropriately and that educational requirements are being met.

The potential for feedback to improve training programmes has made the assessment process popular with trainees in regions where pilot schemes have been running. Adjustment of timetables and attachments to 
balance the experience of trainees has proved less complex than expected. The assessments have also given trainees the opportunity to gain more comprehensive career advice than in the past and from several sources.

Finally there are the natural concerns of those who will be asked to undertake the assessments. It is essential that they are given time to undertake this difficult work and that they are trained in the assessment process. We expect that with the forecast reductions in numbers of trainees it should be possible for the annual assessments in each region to be completed in a single day each year.

It is vital that the assessment process is seen to be fair. With this in mind the SAC have devised a proforma for assessment and if this is taken up nationally discrepancies between regions will be kept to a minimum. We can expect the full cooperation of trainees only if all face the same hurdles.
We realise that the published guidelines are only a start. Though every effort was made to ensure wide consultation, modifications will be needed. We are keen to receive advice and criticism from readers so that the guidelines can be improved.

Department of Cardiology,

RM BOYLE

York District Hospital,

Wigginton Road,

York YO3 $7 \mathrm{HE}$

Department of Cardiology,

University College of Wales,

RJC HALL

Cardiff

1 Hall RJC, Boyle RM, Webb Peploe M, Chamberlain DA, Parker DJ. Guidelines for specialist training in cardiology. Br Heart $\mathcal{f}$ (in press).

2 Hospital Doctors: Training for the Future (The Report of the Working Group on Specialist Medical Training). Department of Health; 1993. 